Document downloaded from:

http://hdl.handle.net/10251/138905

This paper must be cited as:

Juste-Dolz, AM.; Do Nascimento, NM.; Monzó, IS.; Grau-García, E.; Roman-Ivorra, JA.; López-Paz, JL.; Escorihuela Fuentes, J.... (07-2). New structural insights into the role of TROVE2 complexes in the on-set and pathogenesis of systemic lupus eythematosus determined by a combiantion of QCM-D and DPI. Analytical and Bioanalytical Chemistry. 411(19):4709-4720. https://doi.org/10.1007/s00216-018-1407-x

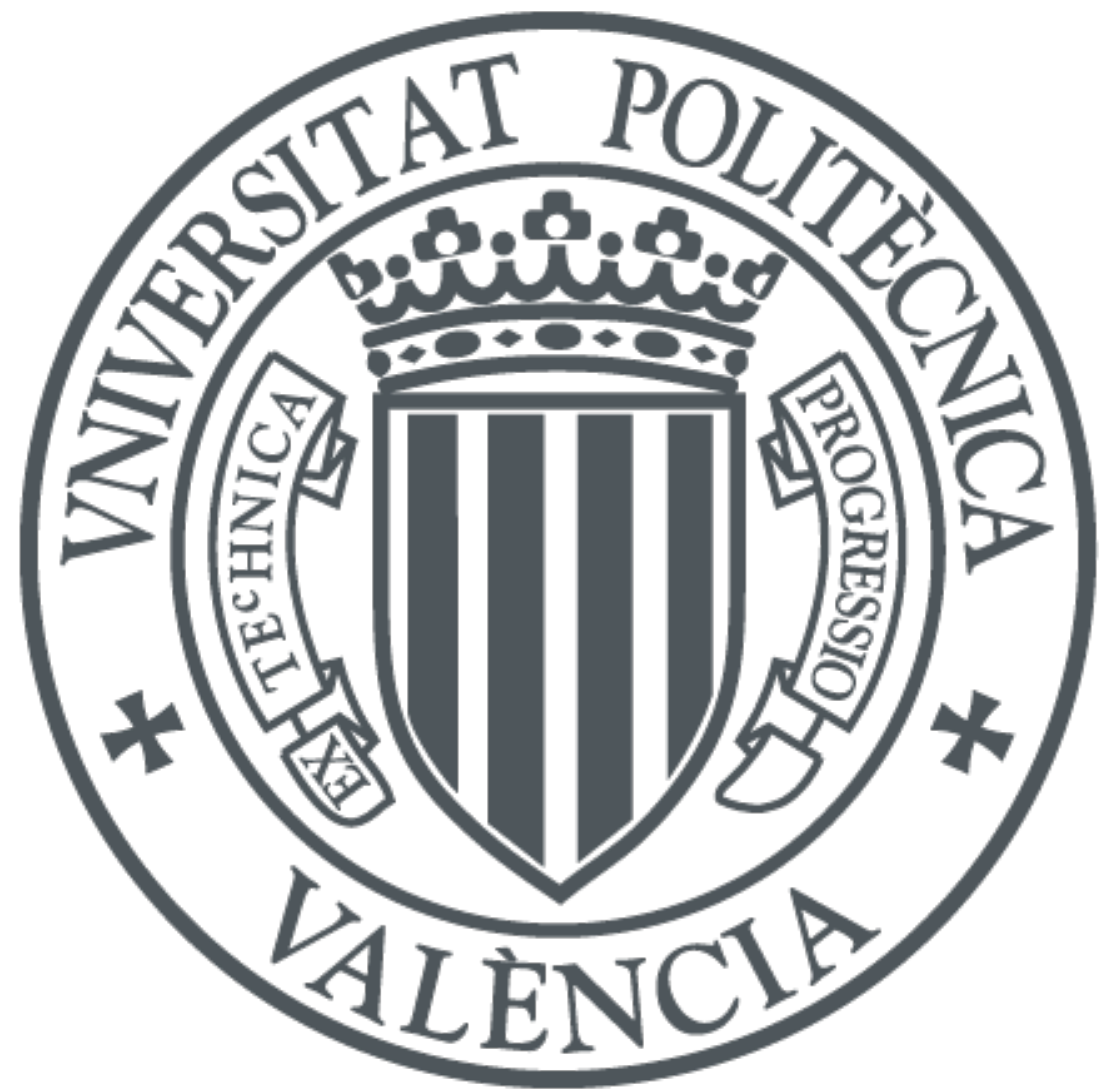

The final publication is available at

https://doi.org/10.1007/s00216-018-1407-x

Copyright Springer-Verlag

Additional Information

The final publication is available at link.springer.com. 


\section{New Structural Insights into the Role of TROVE2 Complexes in the on-set and Pathogenesis of Systemic Lupus Erythematosus Determined by Combination of QCM-D and DPI}

Augusto Juste-Dolz ${ }^{1}$, Noelle M. do Nascimento ${ }^{2}$, Isidro Monzó ${ }^{1}$, Elena Grau-García ${ }^{3}$, Jose A. Román-Ivorra ${ }^{3}$, José Luis Lopez-Paz ${ }^{2}$, Jorge Escorihuela ${ }^{4}$, Rosa Puchades ${ }^{2}$, Sergi Morais $^{2}$, David Gimenez-Romero ${ }^{1 *} \&$ Ángel Maquieira ${ }^{2 *}$

${ }^{1}$ Departamento de Química-Física, Universitat de València, C/ Dr. Moliner 50, 46100 Burjassot, Spain.

${ }^{2}$ Departamento de Química, IDM, Universitat Politècnica de València, Camino de Vera, s/n Valencia, 46022, Spain.

${ }^{3}$ Departamento de Reumatología, Hospital Universitario y Politécnico La Fe, and Rheumatology Research Group, Instituto de Investigación Sanitaria La Fe, Avenida de Fernando Abril Martorell $\mathrm{n}^{\circ}$ 106, 46026 Valencia, Spain.

${ }^{4}$ Departamento de Química Orgánica, Universitat de València, C/ Dr. Moliner 50, 46100 Burjassot, Spain.

Correspondence and requests for materials should be addressed to

David Gimenez-Romero (giroda@uv.es)

Ángel Maquieira. (amaquieira@qim.upv.es )

KEYWORDS: TROVE2, antibody bipolar bridging, Systemic Lupus Erythematosus, epitope mapping, QCM-D, Dual Polarization Interferometry. 


\begin{abstract}
The mechanism of self-recognition of the autoantigen TROVE2, a common biomarker in autoimmune diseases, has been studied with Quartz Crystal Microbalance with Dissipation monitoring (QCM-D) and Dual Polarization Interferometry (DPI). The complementarity and remarkable analytical features of both techniques has allowed to achieve new insights onto the onset of systemic Lupus Erythematosus (SLE) at the molecular level.
\end{abstract}

The in vitro study for SLE patients and healthy subjects suggests that anti-TROVE2 autoantibodies may undergo an antibody bipolar bridging. An epitope-paratope specific binding initially occurs to activate a hidden Fc-receptor in the TROVE2 tertiary structure. This bipolar mechanism may contribute to the pathogenic accumulation of anti-TROVE2 autoantibody immune complex in autoimmune disease. Furthermore, the specific calcium dependent protein-protein bridges point out at how the TRIM21:TROVE2 association might occur, suggesting that the TROVE2 protein could stimulate the intracellular immune signaling via the TRIM21 PRY-SPRY domain. These findings may help to better understand the origins of the specificity and affinity of TROVE2 interactions, which might play a key role in the SLE pathogenesis.

This manuscript gives one of the first practical applications of two novel functions ($\mathrm{df} / \mathrm{dD}$ and $\Delta \mathrm{h} / \mathrm{molec}$ ) for the analysis of the data provided by QCM-D and DPI. In addition, it is the first time that QCM-D has been used for mapping hidden Fc-receptors as well as linear epitopes in a protein tertiary structure. 


\section{INTRODUCTION}

Systemic Lupus Erythematosus (SLE) is a chronic inflammatory autoimmune disease characterized by flares when symptoms arise, and periods of remission when symptoms are under control [1]. The disease affects nearly every organ of the human body, mainly the skin, heart, lungs and intestines [2]. SLE is one of the most unpredictable, and devastating diseases associated with a high morbi-mortality [3].It is also considered the prototype systemic autoimmune disease, affecting 40-50 persons per 100,000 with a 9:1 ratio prevalence female to male [4].

SLE is characterized by the over-production of proteins and autoantibodies, whose immune complexes induce tissue inflammation and destruction in important organs as the kidney and brain. Its clinical manifestation is well known and characterized, however, the complex mechanism of on-set is not well understood. There is a strong evidence that it is presumably initiated by unknown environmental factors, acting on persons with defects in the immune system [5]. For that, patients are being currently treated by a drug BENLYSTA ${ }^{\circledR}$ (belimumab)- targeted to inhibit the B-cell activating factor that is responsible for part of the normal immune response, and also for the over-aggressive immune response. Other drugs are under investigation or never reached the market. Nonetheless, the vast majority of therapies have been designed using the same strategy that is being employed for other autoimmune diseases with inflammatory components, such as rheumatoid arthritis, Inflammatory Bowel Disease, psoriasis, etc. While they are quite successful in ameliorating some of the symptoms of these diseases, the biologics and small drugs employed are not effective in all patients and, often, have devastating side effects. Thus, there is a need for more effective therapies for SLE. Current therapeutic agents do not directly target specific pathways for SLE mostly because there is not enough information on the nature of the mechanism of the disease at the molecular level. The 
knowledge of this mechanism is important as it could lead to the design of new targets for therapeutic intervention that could result in more specific drugs and better outcomes for patients.

Anti-Ro/SSA autoantibodies are the most prevalent specificity among many autoimmune diseases, such as SLE, Sjögren's syndrome, systemic sclerosis, idiopathic inflammatory myopathies, rheumatoid arthritis or primary biliary cirrhosis. Among them, the Ro ribonucleoprotein complex (Ro/SSA RNP complex) is a major antigen, targeted by autoantibodies in patients suffering from SLE [6].It is composed of one of the four small cytoplasmic RNAs and at least two proteins; the 60-kDa protein Ro60/TROVE2 and the 48-kDa phosphoprotein La [7].A third protein of molecular mass $52 \mathrm{kDa}$ (Ro52/TRIM21) has also been reported to be associated with this multiprotein, but this association has not been proven so far [8].No binding site for TRIM21 has been identified yet, suggesting that the association of TRIM21 with Ro should be mediated via interaction with TROVE2, see Figure 1 [10]. 


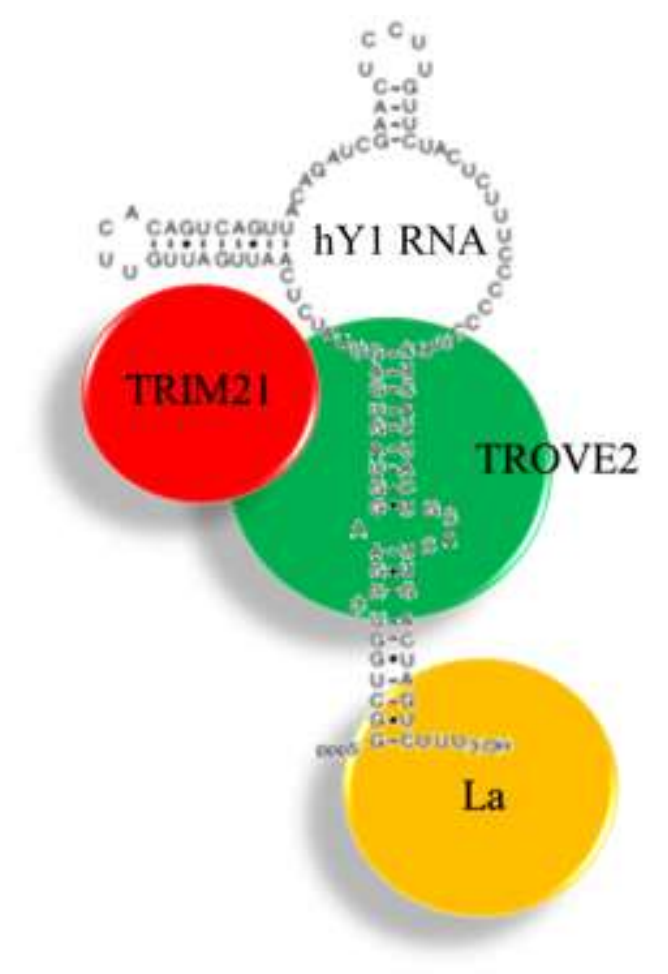

Figure 1.- Scheme of the Ro/SSA RNP complex.

In contrast to the well-characterized ribonucleoproteins, the function of the Ro protein complex, associated with noncoding RNAs (ncRNAs) has been an enigma for over 30 years. Rather recently, it has been postulated that the role of the protein complex in biological processes might be the same than that played by its respective subunits, i.e., the TRIM21 and TROVE2 proteins [11].

TROVE2 is a 538 a.a. protein [12] which is an important member of the nuclear antigen family and a common biomarker of autoimmune diseases [13]. TROVE2 binds synergistically to a sequence of ncRNAs known as YRNAs [14], allowing to constitute a stable complex with exoribonuclease polynucleotide phosphorylase, a RNA degradation protein [11]. Consequently, the main known function of TROVE2 is to perform a quality control of misfolded ncRNA (such as Alu RNAs and pre-5S rRNAs), to enhance the cell survival $[13,15]$. 
The human TROVE2 structure has not fully been elucidated, however, two domains of the Xenopus laevis (also known as the African claw-toed frog) have been solved [9], namely, the Telomerase, Ro and Vault (TROVE) and von Willebrand factor A (vWFA). The TROVE domain is a doughnut-shape domain consisting of 7 helical HEAT-like repeats [16].The von Willebrand factor A domain is present in a large number of proteins involved in cell adhesion such integrins [17]. The vWFA has a metal ion-dependent adhesion site (MIDAS) motif (D-x-S-x-S...T...D) where divalent cations can bind, rearranging the tertiary structure of the protein and mediating the ligand binding [18].

Anti-TROVE2 autoantibodies are produced in large amounts by the immune system in patients suffering from SLE and can be detected years before the disease manifestation, providing with a detection target for early diagnosis of SLE. Epitope mapping studies showed that TROVE2 has a conformational epitope between 169-190 a.a. [19]. These amino acids reside in a loop involved in binding single-stranded RNA, so anti-TROVE2 antibodies target a key part for its functional mechanism [11]. Thus, although the underlying cause of SLE is not fully defined, it has been hypothesized that it is related to the cellular function of the TROVE2 protein [20].

Quartz Crystal Microbalance with Dissipation monitoring (QCM-D) has been widely used for biosensing, given its remarkable analytical features. However, few studies have been carried out using QCM-D together with Dual Polarization Interferometry (DPI), a complimentary method to it for measuring the supramolecular conformation of adsorbed films [25], another label-free technique which provides real-time results of mass and thickness with a very high resolution $\left(0.1 \mathrm{pg} / \mathrm{mm}^{2}, 0.1 \AA\right)$. The joint use of both techniques provides important advantages, such as the determination of the mass of water within the adlayer, which plays a very important role in biochemical processes. Moreover, the use of two novel functions: $-\mathrm{df} / \mathrm{dD}$ and $\Delta \mathrm{h} / \mathrm{molec}$, recently reported [24] allows the 
detection and characterization of reaction intermediates in situ, showing the effect of the hydrodynamic flow during the biomolecular interaction. These techniques have never previously been used to monitor reaction intermediates in this way.

In the herein reported study, conformational dynamic studies performed with QCM-D and DPI have provided new insights into the mechanism of the on-set of SLE at the molecular level. Specifically, we present the origins of specificity and affinity of TROVE2 interactions in SLE patients and healthy subjects. Studies of biomolecular conformations were performed using a novel methodology to analyze data of QCM-D. This technique was used together with DPI [25], another label-free technique which provides real-time results of mass and thickness with a very high resolution $\left(0.1 \mathrm{pg} / \mathrm{mm}^{2}\right.$, $0.1 \AA$ ). Furthermore, QCM-D has been used for the first time to map hidden Fc-receptors in the protein tertiary structures, as well as to map linear epitopes.

The achieved results revealed an antibody bipolar bridging mechanism for the TROVE2autoantibody interaction. We discovered that the specific calcium dependent proteinprotein interactions (or bridges) point out how the TRIM21-TROVE2 synergy might occur. The results suggested that the chemistry of TROVE2 might play a key role in regulating the intracellular immune response, providing a better understanding of the SLE disease. We envision that this new information could lead to the design of novel more specific therapeutic interventions for SLE.

\section{MATERIAL AND METHODS}

Ethics Statement. Approval from the Biomedical Research Ethics Committee of La Fe Hospital was obtained to conduct this study. All patients agreed to take part in the study and for their samples to be stored in La Fe Biobank, and gave their informed written consent to be included in the study. All experiments were performed in accordance with relevant guidelines and regulations. 
Serum Samples. Hundred sixty samples from patients with SLE and eight control samples (healthy subjects) were obtained from the Departamento de Reumatología, Hospital Universitario y Politécnico La Fe, Valencia (Spain). Blood samples were collected by venipuncture of the patient's forearm vein, and were processed immediately after extraction, they were handled by standard procedures and stored at $-80^{\circ} \mathrm{C}$ in $\mathrm{La} \mathrm{Fe}$ Biobank. All patients satisfy the SLICC validated the classification criteria to be diagnosed as SLE. To develop a diagnostic for SLE patients at all stages of the disease, our calibration serum pool contained samples of fifteen and eight sera from anti-Ro+ patients with SLE (anti-Ro $>200 \mathrm{U} / \mathrm{mL}$ ) and healthy subjects (anti-Ro $<15 \mathrm{U} / \mathrm{mL}$ ), respectively.

hIgG Purification. Immunoglobulins type $\mathrm{G}$ (IgGs) were purified by affinity chromatography (GE Healthcare, HiTrapTM protein G HP) following the manufacturer protocol. The purified hIgGs were concentrated using ultrafiltration (Pall Corporation, Macrosep ${ }^{\circledR}$ Advance Centrifugal Device, 30K MWCO). Finally, the concentration of anti-TRIM21 and anti-TROVE2 autoantibodies were quantified by means of human antiSSA(Ro-52) and human anti-SSA(Ro-60) ELISA kits (Signosis-Biosignal Capture). The optical density of each well was measured using a microplate reader (Wallac, Victor 1420 multilabel counter) at $450 \mathrm{~nm}$. Biostatistical analysis was performed using the R software version 3.2.3.

Quartz crystal microbalance with dissipation monitoring (QCM-D). QCM-D measurements were carried out using commercially available gold Q-sense sensors (5 MHz, QSX 301, Biolin Scientific). The frequency and dissipation variations were monitored using Q-Sense E1 (Biolin Scientific, Sweden) device equipped with a liquid flow cell setup. All experiments were carried out in the phosphate buffered saline $(1 \mathrm{x}$ PBS, $10 \mathrm{mM}$ phosphate, $137 \mathrm{mM} \mathrm{NaCl}, 2.7 \mathrm{mM} \mathrm{NaCl}, \mathrm{pH} 7.4$ ) solution to dissolve 
protein and the resonance frequency was stabilized in 1x PBS. The flow rate was 50 $\mu \mathrm{L} / \mathrm{min}$ at $25^{\circ} \mathrm{C}$.

Prior to use, the Q-sense sensors were irradiated at $254 \mathrm{~nm}$ for $10 \mathrm{~min}$ and heated at $75^{\circ}$ C with a 5:1:1 mixture of mili-Q water, ammonia (25\%) and $\mathrm{H}_{2} \mathrm{O}_{2}(30 \%)$ for 5 min. At the end, the sensors were irradiated again for $10 \mathrm{~min}$.

Self-Assembly Monolayer (SAM). SAM was prepared by treating the quartz crystal with 10mM of MPA (3-mercaptopropionic acid, Sigma-Aldrich) overnight and then activated with $46 \mathrm{mM}$ of EDC -N-ethyl-N'-(3-dimethylaminopropyl) carbodiimide, SigmaAldrich, purum grade-/NHS (N-hydroxysulfosuccin-imide 98\%, Sigma-Aldrich) for an hour to produce a carboxyl chip.

Immobilization of C-terminal of protein on hydrazine chip. Hydrazine chip was prepared by converting carboxyl group on SAM to hydrazide group by treating with 5 mM carbohydrazide $98 \%$ (Sigma-Aldrich) before protein immobilization. One hundred microliter of TROVE2 (recombinant human RO-60/SS-A expressed in Escherichia coli (E. coli), long isoform, ProSpec), or TRIM21 (recombinant human RO-52/SS-A expressed in E. coli, Sigma-Aldrich), was added at the dose of $33 \mathrm{mg} / \mathrm{L}$ (around 49 $\mathrm{ng} / \mathrm{cm} 2$, saturation probe), and incubated for an hour to be cross-linked to the activated gold surface via its $\mathrm{N}$-terminal amino group. Uncrosslinked residues were blocked by 1 $\mathrm{M}$ ethanolamine-HCl $\geq 98 \%$ (Sigma-Aldrich) and a blocking buffer containing $1 \mathrm{mM}$ ethylenediaminetetraacetic acid (Riser), $0.25 \%$ bovine serum albumin (BSA, SigmaAldrich, $\geq 98 \%$ agarose gel electrophoresis), and 0.05\% Tween-20 (Scharlau, synthesis grade). All reaction time was $1 \mathrm{~h}$ and sensor chip was cleaned using mili-Q-water between the reactions. 
Immobilization of $\mathrm{N}$-terminal of polypeptides on carboxyl chip. After abovementioned treatment and rinsing with mili-Q-water, $33.3 \mathrm{mg} / \mathrm{L}$ of polypeptide sequences (peptides\&elephants) were added to the chip. Each polypeptide was terminated by an amino acid with a free amine group, and an amide group at its $\mathrm{C}$-terminus. Those chips were then blocked with $20 \mathrm{mg} / \mathrm{mL}$ of D-glucamine 95\% (abcr) in 1x PBS, pH 9.75 and rinsed with mili-Q water.

Immobilization steps were characterized by Static Water Contact Angle (SCA), Polarization Modulation Infrared Reflection Absorption Spectroscopy (PM-IRRAS) and X-ray Photoelectron Spectroscopy (XPS) with a high precision, following the procedures reported in a previous manuscript [21]. In all cases, data confirmed the formation of hydrophilic SAMs of TROVE2 with a high structural order and surface homogeneity.

Dual Polarization Interferometry. DPI measurements were carried out by an Analight Bio200 Dual Polarization Interferometer (Biolin Scientific, Sweden) consisted of a helium neon laser $(\lambda=632.8 \mathrm{~nm}$ and $20 \mathrm{~mW})$, a $1024 \times 1024$ element-imaging device and a sensor chip clamped inside a thermally insulated chamber (temperature control within $0,27315^{\circ} \mathrm{C}$ ). The state of polarization of light was switched on a $2 \mathrm{~ms}$ cycle between transversal electric and magnetic modes using a ferroelectric crystal, before passing through the sensor. The interference pattern formed in the far-field was detected on the opposing side by the element-imaging device. Data acquisition and treatment were carried out by using Analight DAQ (Biolin) and Analight Explorer (Biolin) software packages, respectively. Solutions were flowed by a double-channel precision syringe pump (Harvard Apparatus PHD 2000 Infusion, Kent, UK) and the injections were carried out by using two high-performance chromatography valves connected in series. During the entire experiment the flow was maintained at a constant rate of $20 \mu \mathrm{L} / \mathrm{min}$, and all solutions were injected in volumes of $250 \mu \mathrm{L}$. 
Chip activation. The activation of the DPI chip (FB100, Farfield, UK) was achieved by immersing the chip overnight in chromic mixture $\left(100 \mathrm{~g} / \mathrm{L} \mathrm{K}_{2} \mathrm{Cr}_{2} \mathrm{O}_{7}\right.$ in $\left.85 \% \mathrm{H}_{2} \mathrm{SO}_{4}\right)$, the chip was then rinsed with deionized water and dried with nitrogen; after that it was submerged in $20 \% \mathrm{HNO}_{3}$ for $2 \mathrm{~h}$. After rinsing with deionized water and drying with nitrogen the activated chip was immersed in 1\% carboxyethyl silanetriol (CEST) for $1 \mathrm{~h}$ and after cleaning with water it was placed in an oven at $110^{\circ} \mathrm{C}$ for $1 \mathrm{~h}$. A $1 x$ PBS solution filtered through a $0.45 \mu \mathrm{m}$ PVDF filter and degassed by sonication was used as carrier. That solution was also used to prepare the solutions injected unless otherwise stated. With the treated chip mounted on the setup an injection of 0.2 M 3-(3-dimethylaminippropyl)carbodiimide (EDC) and 0.05 M N-hydroxysuccinimide (NHS) in water followed by an injection of $5 \mathrm{mM}$ of carbohydrazide in water were done. TROVE2 (recombinant human RO-60/SS-A expressed in E. coli, long isoform, ProSpec) was then immobilized by covalent binding by injecting a $60 \mathrm{mg} / \mathrm{L}$ solution of this protein. After that an injection of $20 \mathrm{~g} / \mathrm{L}$ of glucamine in 1x PBS (pH 9.75) was performed. Finally, a $300 \mathrm{mg} / \mathrm{L}$ solution of purified hIgGs from SLE patients sera was injected in one channel and a $300 \mathrm{mg} / \mathrm{L}$ solution of serum from healthy subjects was injected in the other channel. To study the effect of calcium ions on the TRIM21-TROVE2 interaction, a $33 \mathrm{mg} / \mathrm{L}$ TRIM21 solution was immobilized instead of TROVE2 and a $50 \mathrm{mg} / \mathrm{L}$ TROVE2 solution in PBS with $\mathrm{Ca}^{2+}$ $100 \mathrm{mM}$ was injected instead of sera solutions; $100 \mathrm{mM}$ of $\mathrm{Ca}^{2+}$ was added to the PBS used as carrier to perform this injection.

Assays. Four experimental parameters were measured: the dissipation factor and resonance frequency changes, provided by QCM-D, and the variations of mass and thickness, provided by DPI. All measurements were performed in triplicate, being their reproducibility within 5 to $10 \%$ for a measurement rate of 200 data points per second. 
Consequently, the reported results are based on a high number of experimental data (e.g the kinetic parameters were fitted with 80,000 data points).

On the other hand, as shown in supplementary material, there was a negligible interaction between TROVE2 and BSA, Fc fragments and non-specific IgGs, over a wide range of concentrations. Furthermore, the control for immobilized BSA with IgG was also zero at all concentrations tested. Consequently, it is possible to establish that nonspecific interactions were negligible.

\section{RESULTS}

The experiments performed toward elucidating the mechanism of on-set of SLE shed important light into the dynamic interactions of TROVE2 and TRIM21 with other molecules such as the SLE autoantibodies. With this aim, we carried out a series of experiments employing samples from individuals with SLE and healthy controls. We first focused our attention to the formation of the complexes between TROVE2 and the autoantibodies. This antigenic complex formation, TROVE2-autoantibodies, was followed by QCM-D. For this purpose, recombinant human TROVE2 protein expressed in E. coli was immobilized on a gold QCM-D sensor using a hydrophilic self-assembled monolayer (SAM) with a high structural order and homogeneity [21]. The surface concentration of protein immobilized on the sensor was $194 \mathrm{ng} / \mathrm{cm}^{2}$.

Antigen-antibody interactions are influenced by the bulk concentration of the protein in solution. For that, the change of the surface density of the antigenic complex with antiTROVE2 autoantibodies (hIgGs) concentration was studied in a steady state [21].The results obtained with the human samples revealed a cooperative binding between the autoantigen TROVE2 and the circulating autoantibodies, as well as a different binding equilibrium for SLE patients and control subjects. However, it is important to emphasize 
that the monitored signal was free from unspecific interactions, since the piezoelectric response of the negative control, bovine serum albumin (BSA), was negligible for all concentrations tested ([50-2,000] mg/L, see Supplementary Figure 1). Furthermore, the presence of human Fc-receptors in the TROVE2 protein could be also discarded, given that the evolution of the piezoelectric signal was nearly zero when active human antibody Fc fragments were flowed through the sensor $([50-2,000] \mathrm{mg} / \mathrm{L}$, see Supplementary Figure 2). Consequently, the recognition was only specific with a single epitope-paratope binding involved in the TROVE2-hIgG biorecognition.

\section{Conformational dynamics}

Interactions between proteins and ligands are relevant for regulation of biological processes, because intrinsic conformational dynamics of proteins play crucial roles in ligand binding and dissociation [22,23].Accordingly, the conformational dynamics of the TROVE2 biorecognition was studied here by QCM-D, applying the novel function $-\partial \mathrm{f} / \partial \mathrm{D}$ ( $\partial \mathrm{f}$ and $\partial \mathrm{D}$ are the time derivatives of the frequency and dissipation factor, see Supplementary Note 1) [24].This function provides a clear identification of the structural transitions of the adsorbed layer and allows the reaction path to be monitored in real time. Similarly, Fakhrullin et al. developed a QCM immunosensor with the simultaneous measurement of resonance frequency and motional resistance for the detection of antibodies to double-stranded DNA [26].

As shown in Figure 2a, the $-\partial \mathrm{f} / \partial \mathrm{D}$ plot was found to be a peak-shape function with a maximum centered at $\sim 9 \mathrm{~Hz}$ for both SLE patients and healthy subjects [21]. Consequently, the TROVE2 biorecognition process exhibits similar conformational dynamics with two elementary steps because the $-\partial \mathrm{f} / \partial \mathrm{D}$ plot is always a peak-shape function (Young's modulus of reactive complex, intermediate complex and product 
complex). Indeed, comparable $-\partial \mathrm{f} / \partial \mathrm{D}$ values were obtained for both intermediate states (Int. I and Int. II) and reaction products (PI and PII), suggesting similar structures. Steadystate data also suggested the formation of antigenic complexes with similar structures, since their $-\partial \mathrm{f} / \partial \mathrm{D}$ values are very similar (see Supplementary Table 1).

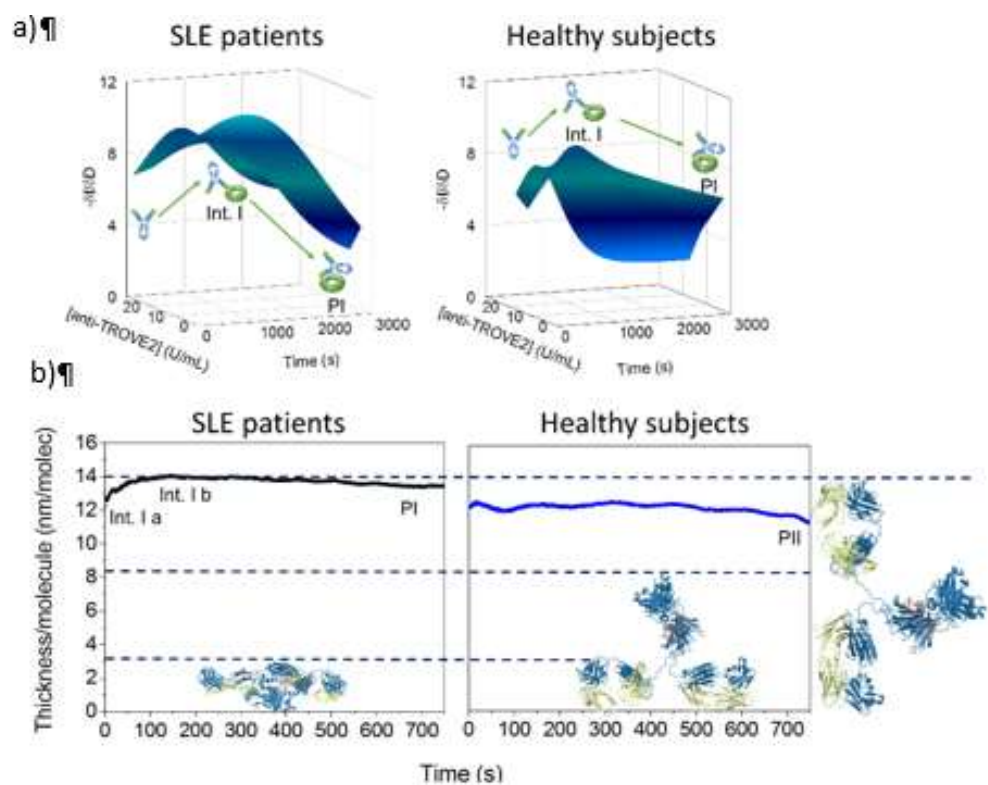

Figure 2 - - Response of the -TROVE2-based-QCM-D biosensor with respect to: a) $-\partial f / \partial D$ ratio for $\cdot \mathrm{IgG}$ - from sera of SLE patients $([\mathrm{SLE} \mathrm{hIgG}]=-18.91 \mathrm{U} / \mathrm{mL}$, left) and healthy subjects $([$ control $\mathrm{hIgG}]=-12.39 \cdot \mathrm{U} / \mathrm{mL}$, right). b) DPI-values of thickness per molecule monitored during the hIgGs:TROVE2 biorecognition for SLEpatients (left and black, $[\mathrm{SLE} \cdot \mathrm{hIgG}] \cdot=4.43 \cdot \mathrm{U} / \mathrm{mL}$ ) and healthy subjects (right and $\cdot$ blue, $[$ control $\mathrm{hIgG}]=$ $15.48 \mathrm{U} / \mathrm{mL}$ ). The antibody structures show the theoretical thicknesses per molecule of different orientations of the antibody molecules on the DPI-sensor surface. .

In order to get more insights about the TROVE2 biorecognition event, this step was also studied by DPI. This label-free technique allows the determination of the thickness and dry mass of bound biological molecules on the adlayer in real-time with resolutions of $0.1 \AA$ and $0.1 \mathrm{pg} / \mathrm{mm}^{2}$, respectively [25].As depicted in Figure $2 \mathrm{~b}$, the changes in thickness per molecule by means of the novel function $\Delta \mathrm{h} /$ molec (see Supplementary Note 2) for hIgGs showed that the TROVE2-autoantibody interaction involves two and one reactive species for SLE patients and control subjects, respectively. Taking into account the antibody dimensions, results monitored by DPI suggest that SLE hIgGs targeted initially the TROVE2 antigen by only one Fab fragment $(\approx 12.2 \mathrm{~nm} /$ molecule, 
Int. Ia). Next, another antibody fragment interacted with the antigen $(\approx 13.4 \mathrm{~nm} / \mathrm{molec}$, $\mathrm{PI})$, being both states connected via a reaction intermediate $(\approx 14.0 \mathrm{~nm} / \mathrm{molec}$, Int $\mathrm{Ib})$.

For healthy subjects (Figure 2b), the hIgGs targeted the TROVE2 antigen by a Fab and another antibody fragment $(\approx 11.4 \mathrm{~nm} /$ molecule, PII $)$. In this context, we took advantage of the complementarity of the two analytical techniques employed. So, the combination of QCM-D results (wet mass) with DPI data (dry mass) allowed us to calculate values of the water content of internally trapped water molecules in the protein. Thus, Figures $2 \mathrm{a}$ and $2 \mathrm{~b}$ show how the structural changes detected by QCM-D during this biorecognition event are more pronounced than those detected by DPI for both SLE and control hIgGs. Hence, this binding must mainly involve changes in the structuring of the surrounding water by the TROVE2 protein in both cases. As water is a major contributor to the protein's 3D structure the protein hydration shell dynamics might play an important role in the TROVE2-hIgG molecular recognition of healthy subjects and SLE patients. However, a complete understanding of the TROVE2 functional mechanism requires a detailed picture of this hydration dynamics for which modelling studies were performed as described below.

\section{Modelling}

As mentioned above, our results revealed two binding sites and two reaction steps for the TROVE2-hIgG molecular recognition in SLE patients and control subjects. However, it was unclear whether these two steps correspond to consecutive or simultaneous processes. QCM data can be used to determinate reaction kinetics [27]. For that and in order to understand the molecular recognition mechanism, a conformational dynamic study was performed either by a L1 and L2 norm minimization. The Akaike Information Criterion (AIC) was used to select the most suitable molecular mechanism for the TROVE2-autoantibodies interaction. The evolution of the piezoelectric signal according 
to the reaction time was simultaneously modelled at different concentrations of antiTROVE2 autoantibody from SLE patients and healthy subjects (see Supplementary Tables 2 and 3). Considering the minimum AIC value (Figure 3), a two-step consecutive reaction model was proposed according to a bivalent recognition process for the autoantibodies.

Figures $3 \mathrm{a}$ and $3 \mathrm{~b}$ show a good agreement between the fitted and the experimental curves, confirming that the proposed binding schemes predicted correctly the TROVE2 autoantibody binding within a wide range of autoantibody concentrations (see Supplementary Table 2). Experiments with increasing concentrations of autoantibodies fit to a first bimolecular association with a rate constant $\left(\mathrm{k}_{\mathrm{on} 1}\right)$ and a dissociation rate constant $\left(\mathrm{k}_{\text {off } 1}\right)$ of around $1.1 \mathrm{~L} \mathrm{U}^{-1} \mathrm{~s}^{-1}$ and $6.8 \cdot 10^{3} \mathrm{~s}^{-1}$, respectively (see Supplementary Table 3). The second association constant $\left(\mathrm{k}_{\mathrm{on} 2}\right)$ is $3.8 \cdot 10^{4} \mathrm{~s}^{-1}$ and its corresponding dissociation constant $\left(\mathrm{K}_{\mathrm{off} 2}\right) 8.2 \cdot 10^{4} \mathrm{~s}^{-1}$, yielded a kinetic dissociation constant $\left(\mathrm{K}_{\mathrm{d}}\right)$ of $9 \mathrm{U}$ $\mathrm{mL}^{-1}$. According to these data, the affinity of anti-TROVE2 autoantibodies for TROVE2 is high and practically independent of the hIgG source, suggesting that both epitopes must be structurally similar. 
a)

b)
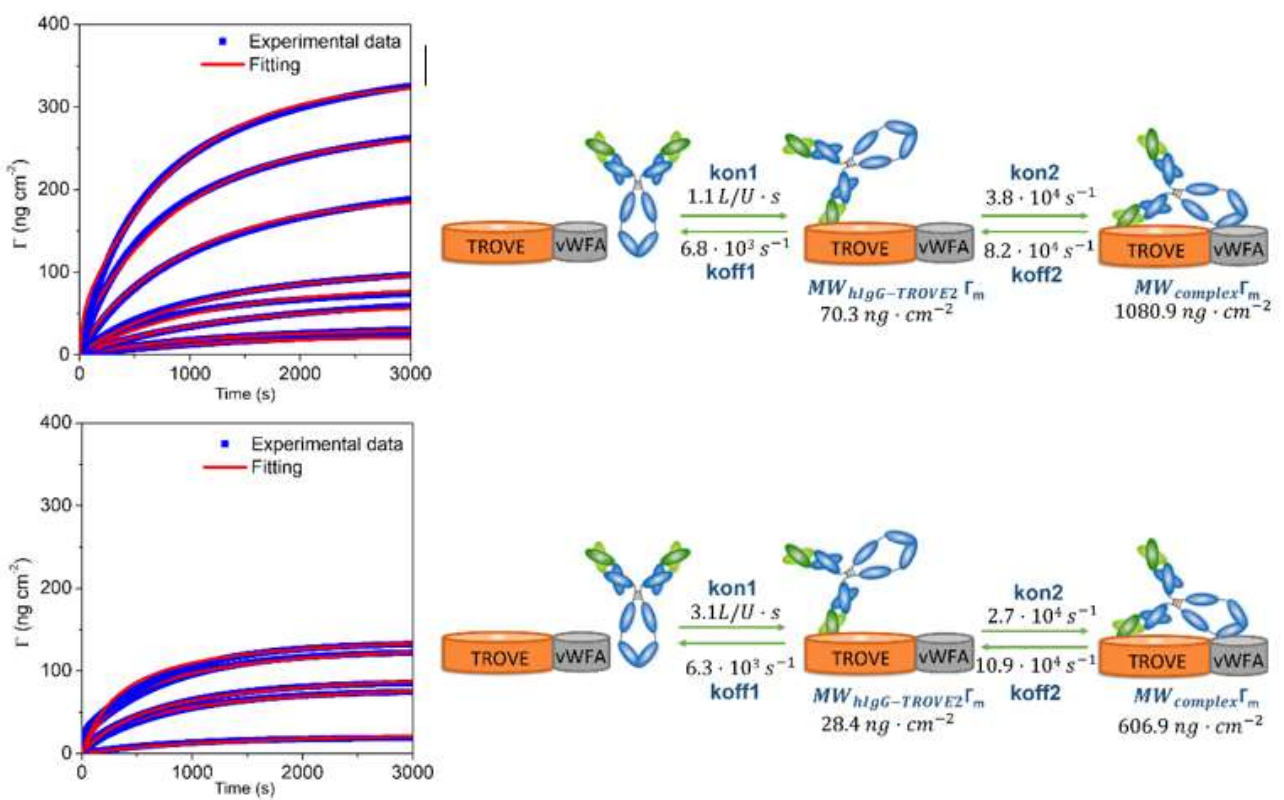

Figure 3.- Real time relaxation curves ( $\Delta \Gamma$ evolution as function of time) of the hIgG-TROVE2 interaction for different antibody concentrations obtained from sera of a) SLE patients and b) healthy subjects. Red lines are the fittings from the kinetic parameters shown on the reaction mechanism. Only one point from ten measured points was taken for all plots.

The main difference observed during the hIgG-TROVE2 binding between SLE patients and healthy subjects lies in the molecular weight of the involved antigenic complexes. Figure 3 shows how reaction products are always heavier than reaction intermediates, $\mathrm{MW}_{\mathrm{hIgG}-\mathrm{TROVE} 2}<\mathrm{MW}_{\text {complex. }}$ As mentioned above, this difference is due to autoantibodydependent modifications of the surrounding water that occurred during the biorecognition process. This is an important finding, since water is a major contributor to a protein's three-dimensional, 3D structure [28], and any change in the TROVE2 tertiary structure could occur during the TROVE2-autoantibody binding.

More important structural changes in the surrounding water were observed in hIgGs of sera from SLE patients than in hIgGs from healthy subjects. A MW $W_{\text {SLEpatients }} / \mathrm{MW}_{\text {healthyubjects }}$ ratio of 1.8 was determined from QCM-D data. This ratio shows how the molecular weight of the antigenic complex composed of autoantibodies from SLE patients is almost twice that of the autoantibodies from control subjects. The 
obtained results show how the conformational structure of the antigenic complexes is dependent on the origin of autoantibodies, facilitating the water motions and accelerate its hydration as appropriate. As the molecular weight of the autoantibodies is independent on the antibody origin, this result again corroborates a change in the TROVE2 tertiary structure during the TROVE2-autoantibody binding. Accordingly, Born et al. demonstrated that the water dynamics in a protein is controlled by its flexibility [29].

The mechanism proposed herein for the TROVE2-hIgG biorecognition takes place by a cooperative interaction. It is possible that these two steps were one Fab binding first and then the other Fab on the IgG or Fab binding followed by a Fc binding. We suggest that this process occurs via an antibody bipolar bridging mechanism, i.e., the antibody binds to the autoantigen through its Fab and concomitantly to a Fc binding site. To prove the model, and although Fc binding sites are not found on the TROVE2 (see Supplementary Figure 2), the results showed in Figure $4 \mathrm{a}$ demonstrated that the $\mathrm{F}\left(\mathrm{ab} \mathrm{b}^{\prime}\right)_{2}$ interaction involves conformational changes of TROVE2 that eventually expose specific sites to the Fc fragments of the autoantibodies. This is in agreement with the above change monitored during this recognition in the TROVE2 tertiary structure. Furthermore, the Fab fragments do not bind twice. Hence, we believe that this activation of the "hidden" Fc binding site by $\mathrm{F}\left(\mathrm{ab}^{\mathrm{c}}\right)_{2}$ fragments is an important step in the chemistry of the TROVE2 protein. 
a)

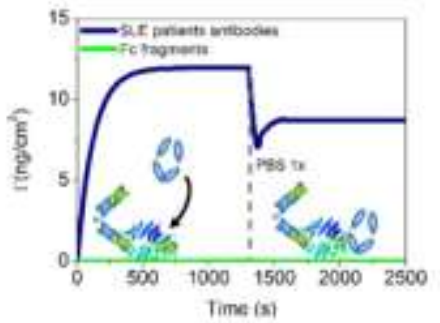

b)

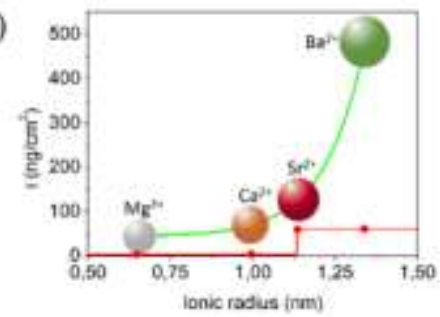

c)

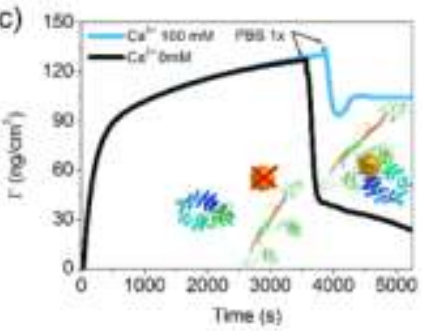

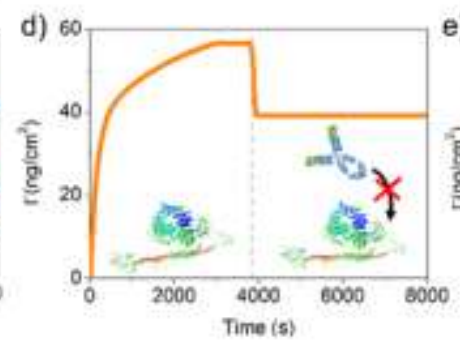

e) 6

Figure 4.- a) Detection of Fc fragments by the TROVE2 protein previous (blue), or not (green), interaction with $\mathrm{F}\left(\mathrm{ab}^{\prime}\right)_{2}$ fragments, b) Influence of the ionic radii of alkaline earth ions in the detection of $\mathrm{Fc}$ fragments. Red line represents the nonspecific interactions with BSA. c) TRIM21TROVE2 interaction in presence ([TRIM21 $\alpha]=50 \mathrm{mg} / \mathrm{L}$, blue) and absence ([TRIM21 $\alpha]=300$ $\mathrm{mg} /$, black) of calcium ions. d) Antibody biorecognition $(12.5 \mathrm{U} / \mathrm{mL})$ by TRIM21 previously blocked with TROVE2. e) TROVE2 biorecognition $(50 \mu \mathrm{g} / \mathrm{mL})$ by TRIM 21 previously blocked with control antibodies (12.5 U/mL).

\section{MIDAS motif}

The vWFA domain of the TROVE2 protein has a metal ion-dependent adhesion site (MIDAS) motif that binds to aspartate and in some cases to glutamate in a divalent cationdependent manner. Subsequently, this motif could be related to the binding chemistry of the TROVE2-autoantibody system. In order to investigate this chemical affinity, the influence of the divalent cation interaction (with a concentration of $100 \mathrm{mM}$ ) on the Fcbinding affinity was studied. As is shown in Figure $4 \mathrm{~b}$ the MIDAS motif acts as a highaffinity Fc-receptor, and the affinity of TROVE2 for the Fc fragments increases as the ionic radii of the divalent cations increases; e.g. $\mathrm{Mg}^{2+}(\mathrm{x})<\mathrm{Ca}^{2+}(1.3 \mathrm{x})<\mathrm{Sr}^{2+}(2.3 \mathrm{x})<$ $\mathrm{Ba}^{2+}(10.5 \mathrm{x})$ (Figure 4b). Nonspecific interactions -negative binding controls- followed the opposite trend, $\mathrm{Ba}^{2+} \approx \mathrm{Sr}^{2+}>\mathrm{Ca}^{2+}=\mathrm{Mg}^{2+}=0$, which agrees with the fact that the coordination geometry of this motif is close in size to the calcium cation. The MIDAS motif (diameter around $1.3 \AA$ ) of TROVE2 provides mainly a calcium coordination site (ionic radius $1.14 \AA$ ), being the Fc binding site exposed when the epitope-paratope 
binding takes place. This finding supports the antibody bipolar bridging mechanism of TROVE2 and the autoantibodies. However, and as the MIDAS motif interacts with different divalent cations, it is important to emphasize that other divalent cations such as $\mathrm{Mg}^{2+}, \mathrm{Ba}^{2+}$ and $\mathrm{Sr}^{2+}$ might also affect the functional mechanism of the TROVE2 protein and consequently, any of these cations could be used in future treatments for autoimmune diseases.

Therefore, the aforementioned results suggest that the MIDAS motif could act as a molecular switch capable of binding the autoantibody Fc fragment, depending on the alkaline earth cation present in solution. Hence, these ions could play a role of crucial importance in the immune signaling stimulus by intracellular antibody-bound pathogens, because its concentration changes during the cellular functions.

\section{Ro/SSA ribonucleoprotein complex}

Despite TRIM21 protein was initially proposed to be part of the Ro/SS-A ribonucleoprotein complex $[8,19]$, the TRIM21-TROVE2 interaction remains unknown. Taking into account that the MIDAS domain has adhesive properties, we suggest that the TRIM21:TROVE2 association could be calcium-dependent. In order to test this hypothesis, the TRIM21-TROVE2 molecular recognition event was monitored in the presence $\left(100 \mathrm{mM} \mathrm{Ca}^{2+}\right)$ and absence of calcium cation. As is shown in Figure $4 \mathrm{c}$, the interaction between both proteins without calcium reaches saturation at $122 \pm 3.0 \mathrm{ng} \mathrm{cm}^{-}$

${ }^{2}$. Nevertheless, the presence of calcium led to a similar value for the maximum signal $\left(136 \pm 3 \mathrm{ng} \mathrm{cm}^{-2}\right.$ ) despite the TRIM21 concentration was decreased by $83 \%$ (from 300 $\mathrm{mg} \mathrm{L}^{-1}$ to $\left.50 \mathrm{mg} \mathrm{L}^{-1}\right)$. Furthermore, the time-dependent stability of this antigenic complex in PBS buffer was also studied. Figure 4c shows how the TRIM21-TROVE2 complex remains stable when the bulk calcium concentration is $100 \mathrm{mM}$ whereas it is completely 
dissociated when this bulk concentration is zero. Hence, the stability of this complex was higher when calcium ions were in the solution, indicating a weak interaction between the TRIM21 and TROVE2 proteins when the solution is free of this ion.

As Figure 4c shows, the TRIM21-TROVE2 binding is a calcium-dependent interaction. Consequently, TRIM21 can be an integral part of the Ro/SS-A ribonucleoprotein complex depending on the calcium intracellular level. Subsequent studies failed to confirm the TRIM21-TROVE2 association [30,31] because the calcium concentration was not considered. Within a typical cell, the intracellular concentration of ionized calcium is roughly $100 \mathrm{nM}$, but that value is subject to increases of 10- to 100 -fold during various cellular functions. In SLE patients, the cytoplasmic levels of TROVE2 antibodies, calcium, TRIM21 and TROVE2 are raised [32,33].Consequently, the link between all these species may be studied for a comprehensive understanding of the SLE disease.

QCM-D data show how the TRIM21-antibody biorecognition does not occur when TRIM21 is blocked with TROVE2 ( $\Gamma_{\text {TRIM}} 21$ blocked with TROVE2 $=\Gamma_{\text {blocked }}+$ antibody in solution $\approx 40$ $\mathrm{ng} / \mathrm{cm}^{2}$, see Figure 4d). Nevertheless, TROVE2 is able to replace antibodies blocking the TRIM21 PRY-SPY domain $\left(\Gamma_{\text {TRIM21 blocked with antibody }}=450 \mathrm{ng} / \mathrm{cm}^{2}>\Gamma\right.$ blocked + TROVE2 in solution $=340 \mathrm{ng} / \mathrm{cm}^{2}$, see Figure $\left.4 \mathrm{e}\right)$. On the other hand, DPI results reveal how the TRIM21-TROVE2 bound involves a negligible change of thickness per molecule $(0.47$ $\mathrm{nm} /$ molec.), because the TRIM21 protein may be in a flat-on manner on the sensor chip. According to these results, the TROVE2 protein should be placed between the two PRYSPRY domains, as shown in Figure 5a. All these experimental evidences confirm that TROVE2 and antibodies compete for the same binding site, being the affinity of the TRIM21 PRY-SPRY domain for TROVE2 higher than for autoantibodies (see Figures $4 \mathrm{~d}$ and $4 \mathrm{e})$. Consequently, TROVE2 and the autoantibodies may have the same biological function regarding the TRIM21 protein. Therefore, the increase of the TROVE2 
cytoplasmic level in SLE patients should stimulate the immune signaling via the TRIM21

PRY-SPRY domain, such as intracellular antibody-bound pathogens provoke.

All the previous data suggest that the Ro/SSA RNP complex formation depends on the TROVE2 and TRIM21 correlation levels. As Figure 5b shows, the serum levels of total anti-Ro/SSA RNP complex, anti-TRIM21 and anti-TROVE2 are correlated in most cases $(\mathrm{n}=130, \mathrm{r}=0.72)$, being statistically significant $(\mathrm{P}<0.0001)$. However, the level of antiTROVE2 subunit is the one that showed the highest influence, because the anti-TRIM21 influence is minimal. Hence, the TROVE2 protein concentration is directly related to the concentration of the Ro/SSA RNP complex, while the coupling of TRIM21 with this complex may be singular depending at experimental conditions, corroborating our proposed calcium-dependent interaction.

a)

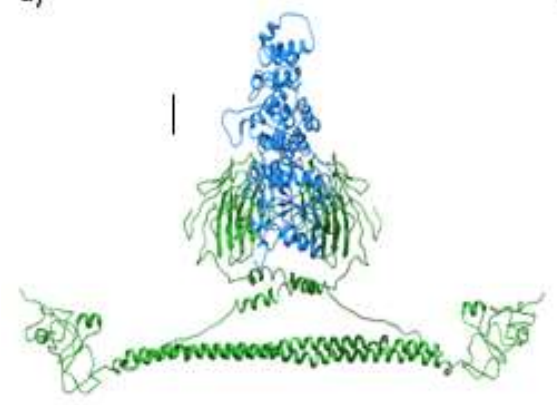

b)

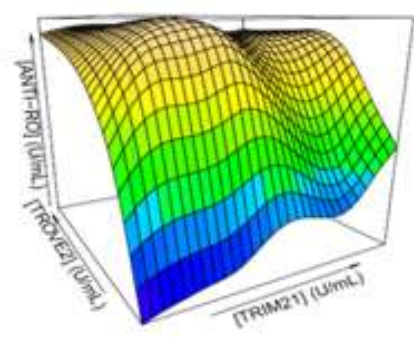

c)
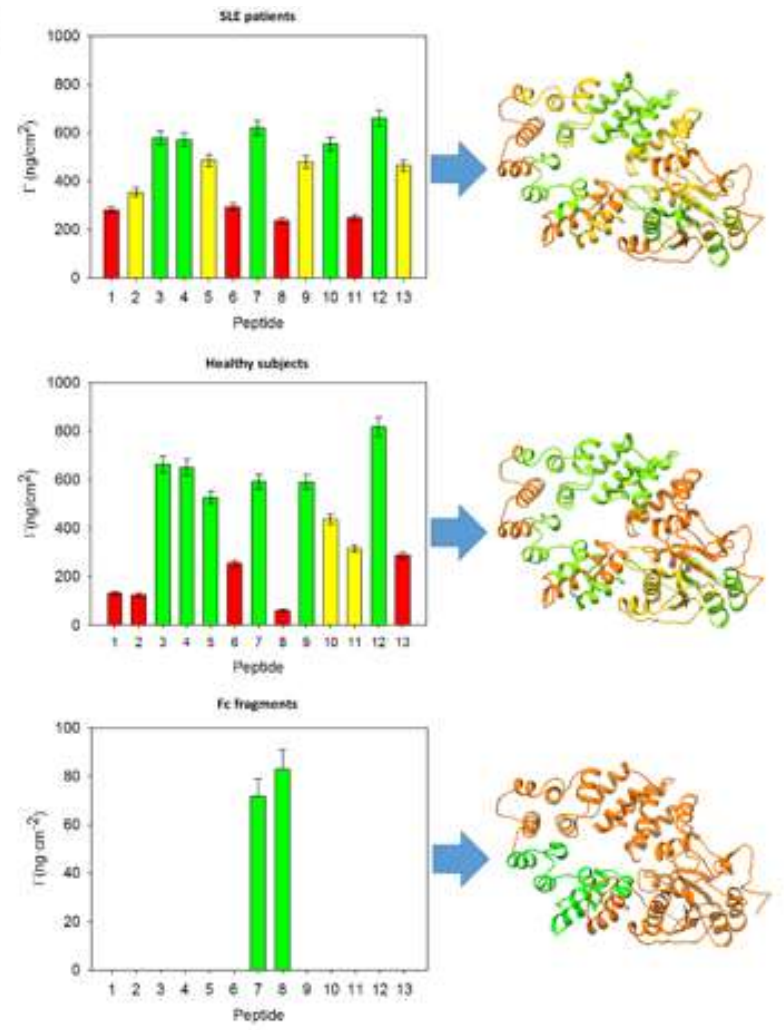

Figure 5.- a) The TRIM21-TROVE2 binding scheme. b) Correlation for serum levels of anti-TROVE2 and antiTRIM21 with levels of anti-Ro (full complex). c) Interaction of different TROVE2 polypeptides (see numeric code in Supplementary Table 4) with hIgGs obtained from SLE patients and healthy subjects as well as with Fc fragments. The binding sites are localized in the TROVE 2 tertiary structure with the same color code than the corresponding bar chart. 


\section{Epitope mapping}

The autoantibodies bind TROVE2 via their Fab regions, thus, it is of utmost importance to identify the epitope region involved in the molecular recognition of the paratope. Several methods are available to epitope map [34,35]. However, we provide here one of the first practical applications of an innovative use of the QCM-D technique to map linear epitopes. For this purpose, the amino acid sequence of the TROVE2 protein (1-538 a.a) was mapped for hIgG-binding epitopes by testing 13 overlapping solid-phase synthetic polypeptides (see Figure 5c), using purified hIgGs from SLE and control sera. Figure 5a shows that the isolated $\mathrm{hIgG}$ proteins from SLE patients react strongly with polypeptides $3,4,7,10$ and 12 while control sera react more efficiently with polypeptides $3,4,5,7,9$ and 12 (see numeric code in Supplementary Table 4). These results confirm that there are no substantial differences in affinity between SLE and control purified hIgGs. In addition, the obtained results also point out the fact that both epitopes must be structurally similar. However, Figure 5c shows how SLE hIgGs target an epitope more localized than the control hIgGs. Understandably, this specific immunity may be acquired naturally by an increase of exposure to antigen in SLE patients. Accordingly, T cells from SLE patients show an increased necrosis as compared with normal T cells [36].

In addition, Figure 5c shows the location of these epitopes within the overall autoantigen domain organization. The region composed by polypeptides 3-5 (80-210 aa) matches with the YRNA binding surface (142-149 and 176-187 aa), so that Fab fragments of antiTROVE2 autoantibodies may block the YRNA binding, according to Stein et al.[12] As a result, it might be concluded that the Fab fragments, during the epitope-paratope binding, should cover the TROVE domain toroidal cavity preventing the single stranded RNA binding, particularly in SLE patients. However, it remains unclear whether the 
autoantibodies against intracellular functional domains are able to influence biological function in vivo.

On the other hand, Fc fragments interact with the vWFA domain of platelet membrane receptors.[37] For the first time, the QCM-D technique has been used for the first time to map Fc-receptors in the protein tertiary structures. We found $\mathrm{Fc}$ interaction with polypeptides 7 and 8 (240-330 a.a., Figure 5c). Our results thus suggest that this region may be a hidden second Fc binding site in TROVE2. Considering the typical antibody dimensions, (10 $\mathrm{nm}$ long, 10-15 $\mathrm{nm}$ high and $2.5 \mathrm{deep}$ ), this binding site cannot be involved in the proposed antibody bridging mechanism as the distance between this Fc binding site and the found epitope is about $4 \mathrm{~nm}$. Hence, this hidden second Fc may only facilitate the formation of the TROVE2 cross-linked autoantibody aggregates.

\section{DISCUSSION}

In this study, we have elucidated the binding mechanism of the TROVE2 biological system in SLE patients and healthy subjects by performing basic in vitro and theoretical assays. Thus, a novel application of the QCM-D and DPI techniques has shown new insights in the mechanism of self-recognition of the autoantigen TROVE2. The circulating anti-TROVE2 autoantibodies are likely to either undergo "autoantibody bipolar bridging" or simultaneous binding of the autoantigen TROVE2 to both Fab and Fc domains. Epitope mapping revealed that anti-TROVE2 autoantibodies unambiguously block the YRNA binding as well as that SLE patients have an increase in specific immunity due to higher exposure to antigen.

In addition to the vWFA domain, a new Fc binding site hidden in the TROVE2 tertiary structure was found, which facilitates the formation of TROVE2 cross-linked 
autoantibody aggregates. Consequently, anti-TROVE2 autoantibodies that undergo TROVE2-mediated bipolar bridging, resulted in their cross-linking and a similar block to Fc $\gamma$ receptor and complement interaction. TROVE2-mediated bipolar bridging can occur by a single IgG bound by a single TROVE2 molecule, or, more likely, one TROVE2 molecule interacting with an anti-TROVE2 autoantibody; that is, bound by the discovered hidden Fc binding site of a second TROVE2 molecule. As the TROVE2 levels increase in SLE patients, it is likely that the resulting cross-linked bipolar-bridged immune complexes form very large protein aggregates.

Autoantibody bipolar bridging could affect autoimmune pathogenesis in several ways. First, bipolar-bridged complexes might contribute to the pathogenic deposition of immune complex in SLE because these large aggregates would not be cleared from the serum of SLE patients. Second, bipolar-bridged autoantibodies associated with TROVE2 on the surface of apoptosing cells could inhibit cell clearance, for example by blocking access to so-called "eat me" signals on the cell surface [38]. This hypothesis could explain the defective clearance of apoptosed cells observed in diseased SLE mice [39].

Furthermore, we have demonstrated that probably subsequent studies failed to confirm the TRIM21-TROVE2 association because the intracellular calcium level was not considered. This binding might occur by means of calcium dependent protein-protein bridges, being located in the TRIM21 PRY-SPRY domain. Accordingly, the calciumdependent association of TRIM21 with TROVE2 might mediate an inflammatory response in SLE patients through the intracellular immune signaling activated by this TRIM21 PRY-SPRY domain, affecting autoimmune pathogenesis. Furthermore, this discovery links the intracellular immune response against antibody-coated viruses, bacteria or prions (TRIM21 protein) with the stabilization and protection from degradation of non-coding RNAs, pre-5S rRNA, and several small cytoplasmic RNA 
molecules known as Y RNAs (TROVE2 protein), which represents a paradigm shift in how we think about viral immunity.

Given the pathogenic role of TROVE2 in systemic autoimmunity, these findings provide new insights into the pathogenesis of SLE disease. As a result, our findings might explain better the regulation of the TROVE2 physiological function and consequently, this information may be of utmost for understanding SLE disease. We believe that the mechanism we unrevealed may have potential applications in the design of new therapies for SLE. Finally, the novel methodology to analyze data of QCM-D and DPI applied here facilitates new insights in mechanisms of protein-protein interactions.

\section{COMPETING INTERESTS}

The authors declare no competing financial and non-financial interests.

\section{ACKNOWLEDGEMENTS}

We would like to thank Sylvia Daunert for her invaluable help with the discussion of the paper. Furthermore, we acknowledge financial support from the Generalitat Valenciana (GVA-PROMETEOII/2014/040) as well as the Spanish Ministry of Economy and Competitiveness and the European Regional Development Fund under award numbers CTQ2013-45875-R and CTQ2013-42914-R.

\section{REFERENCES}


1. Kakatia S, Teronpia R, Barmanb B. Frequency, pattern and determinants of flare in systemic lupus erythematosus: A study from North East India. The Egyptian Rheumatologist 2015;37:S55-S59.

2. Kuhn A, Wenzel J, Weyd H. Photosensitivity, apoptosis, and cytokines in the pathogenesis of lupus erythematosus: a critical review. Clinic Rev Allerg Immunol 2014; $47: 148-162$.

3. American Lupus Foundation (2016). http://www.lupus.org .

4. World Health Organization (2006). Environmental Health Criteria 236, WHO Press, Geneva.Biesen.

5. Li W, Titov AA, Morel L. An update on lupus animal models. Curr. Opin. Rheumatol 2017, 29, 1040-8711.

6. Routsias JG, Tzioufas AG, Moutsopoulos HM. The clinical value of intracellular autoantigens B-cell epitopes in systemic rheumatic diseases. Clin. Chim. Acta 2004;340:1-25.

7. Franceschini F, Cavazzana I. Anti-Ro/SSA and La/SSB antibodies. Autoimmunity 2005;38:55-63.

8. Kelekar A, Saitta MR, Keene JD. Molecular composition of Ro small ribonucleoprotein complexes in human cells. Intracellular localization of the 60- and 52-kD proteins. J. Clin. Ivest. 1994;93:1637-1644.

9. Wolin SL, Reinisch KM. The Ro $60 \mathrm{kDa}$ autoantigen comes into focus: Interpreting epitope mapping experiments on the basis of structure. Autoimmun. Rev. 2006;5:367372.

10. Slobbe RL, Pluk W, van Venrooij WJ, Prujin GJM. Ro ribonucleoprotein assembly in vitro: Identification of RNA-protein and protein-protein interactions. J. Mol. Biol. 1992;2:361-366, 
11. Chen X, Taylor DW, Fowler CC, Galan JE, Wang HW, Wolin SL. An RNA degradation machine sculpted by Ro autoantigen and noncoding RNA. Cell 2013; $153: 166-177$.

12. Stein AJ, Fuchs G, Fu C, Wolin SL, Reinisch KM. Structural insights into RNA quality control: the Ro autoantigen binds misfolded RNAs via its central cavity. Cell 2005;121:529-539.

13. Reed JH, Gordon TP. Autoimmunity: Ro60-associated RNA takes its toll on disease pathogenesis. Nat. Rev. Rheumatol. 2016;12:136-138.

14. Sim S, Weinberg DE, Fuchs G, Choi K, Chung J, Wolin SL. The subcellular distribution of an RNA quality control protein, the Ro autoantigen, is regulated by noncoding Y RNA binding. Mol. Biol. Cell 2009;20:1555-1564.

15. Reed JH, Jackson MW, Gordon TP. A B cell apotope of Ro 60 in systemic lupus erythematosus. Arthritis Rheum. 2008;58:1125-1129.

16. Routsias JG, Tzioufas AG. B-cell epitopes of the intracellular autoantigens Ro/SSA and La/SSB: tools to study the regulation of the autoimmune response. J. Autoimmun. 2010;35:256-264.

17. Whittaker CA; Hynes RO. Distribution and Evolution of von Willebrand/Integrin A Domains:Widely Dispersed Domains with Roles in Cell Adhesion and Elsewere. Mol. Bio. Cell. 2002;13:3369-3387.

18. Lacy DB, Wigelsworth DJ, Scobie HM, Young JA, Collier RJ. Crystal structure of the von WIllebrand factor A domain of human capillary morphogenesis protein 2: An anthrax toxin receptor. Proc. Natl. Acad. Sci. U S A. 2004;101:6367-6372.

19. O'Brien CA, Wolin SL. A possible role for the $60-\mathrm{kD}$ Ro autoantigen in a discard pathway for defective 5S rRNA precursors. Genes \& Dev. 1994;8:2891-2903. 
20. Chen X, Wolin SL. The Ro 60 autoantigen : insights into cellular function and role in autoimmunity. J. Mol. Med (Berl.) 2004;82:232-239.

21. do Nascimento NM, Juste-Dolz A, Grau-García E, Román-Ivorra J, Puchades R, Maquieira A, Morais S, Gimenez-Romero D. Label-free piezoelectric biosensor for prognosis and diagnosis of Systemic Lupus Erythematosus. Biosens. Bioelectron. 2016;90:166-173.

22. Seo MH, Park J, Kim E, Hohng S, Kim HS. Protein conformational dynamics dictate the binding affinity for a ligand. Nat. Commun. 5;3724 (2014).

23. Lakshmanan RS, Efremov V, O'Donnell JS, Killard AJ. Measurement of the viscoelastic properties of blood plasma clot formation in response to tissue factor concentration-dependent activation. Anal Bioanal Chem. 2016;408:6581-6588.

24. do Nascimento NM, Juste-Dolz A, Bueno PR, Monzó I, Tejero R, Lopez-Paz JL, Maquieira A, Morais S, Gimenez-Romero D. Mapping molecular binding by means of conformational dynamics measurements, $R S C A d v$. 2018;8:867-876.

25. Escorihuela J, González-Martínez MA, López-Paz JL, Puchades R, Maquieira A, Gimenez-Romero D. Dual-Polarization Interferometry: A Novel Technique To Light up the Nanomolecular World. Chem. Rev. 2014;115:265-294.

26. Fakhrullin RF, Vinter VG, Zamaleeva AI, Matveeva MV, Kourbanov RA, Temesgen BK, Ishmuchametova DG, Abramova ZI, Konovalova OA, Salakhov MK. Quartz crystal microbalance immunosensor for the detection of antibodies to double-stranded DNA Anal. Bioanl. Chem. 2007;388:367-375.

27. Shen F, Rojas OJ, Genzer J, Gurgel PV, Carbonell RG. Affinity interactions of human immunoglobulin $\mathrm{G}$ with short peptides: role of ligand spacer on binding, kinetics, and mass transfer. Anal. Bioanl. Chem. 2015;408:1829-1841. 
28. Fogarty AC, Laage D. Water Dynamics in Protein Hydration Shells: The Molecular Origins of the Dynamical Perturbation. J. Phys. Chem. B 2014;118:7715-7729.

29. Born B, Kim SJ, Ebbinghaus S, Gruebelebc M, Havenith M. The terahertz dance of water with the proteins: the effect of protein flexibility on the dynamical hydration shell of ubiquitin. Faraday Discuss. 2009;141:161-173.

30. Yoshimi R, Ueda A, Ozato K, Ishigatsubo Y. Clinical and pathological roles of Ro/SSA autoantibody system. Clin. Dev. Immunol. 2012;2012:606195.

31. Boire G, Gendron M, Monast N, Bastin B, Ménard HA. Purification of antigenically intact Ro ribonucleoproteins; biochemical and immunological evidence that the 52kD protein is not a Ro protein. Clin. Exp. Immunol. 1995;100:489-498.

32. Gazzaruso C, Montecucco CM, Geroldi D, Garzaniti A, Finardi G. Severe hypercalcemia and systemic lupus erythematosus. Joint. Bone. Spine 2000;67:485488.

33. Hassan AB, Lundberg IE, Isenberg D, Wahren-Herlenius M. Serial analysis of Ro/SSA and La/SSB antibody levels and correlation with clinical disease activity in patients with systemic lupus erythematosus. Scand. J. Rheumatol. 2002;31:133-139.

34. Huang RY, Chen G. Higher order structure characterization of protein therapeutics by hydrogen/deuterium exchange mass spectrometry. Anal Bioanal Chem. 2014;406:6541-58.

35. Yu F, Roy S, Arevalo E, Schaeck J, Wang J, Holte K, Duffner J, Gunay NS, Capila I, Kaundinya GV. Characterization of heparin-protein interaction by saturation transfer difference (STD) NMR. Anal Bioanal Chem. 2014;406: 3079-89.

36. Rizzuto R, Pozzan T. Microdomains of intracellular Ca2+: molecular determinants and functional consequences. Physiol. Rev. 2006;86:369-408. 
37. Gaipl US, Kuhn A, Sheriff A, Munoz LE, Franz S, Voll RE, Kalden JR, Herrmann M. Clearance of apoptotic cells in human SLE. Curr. Dir. Autoimmun. 2006;9:173187.

38. Falati S, Edmead CE, Poole AW. Glycoprotein Ib-V-IX, a receptor for Von Willebrand factor, couples physically and functionally to the Fc receptor gammachain, Fyn, and Lyn to activate human platelets. Blood 1999;94:1648-1656.

39. Muñoz LE, Lauber K, Schiller M, Manfredi AA, Herrmann M. The role of defective clearance of apoptotic cells in systemic autoimmunity. Nat. Rev. Rheumatol. 2010;6:280-289. 
Graphical Abstract

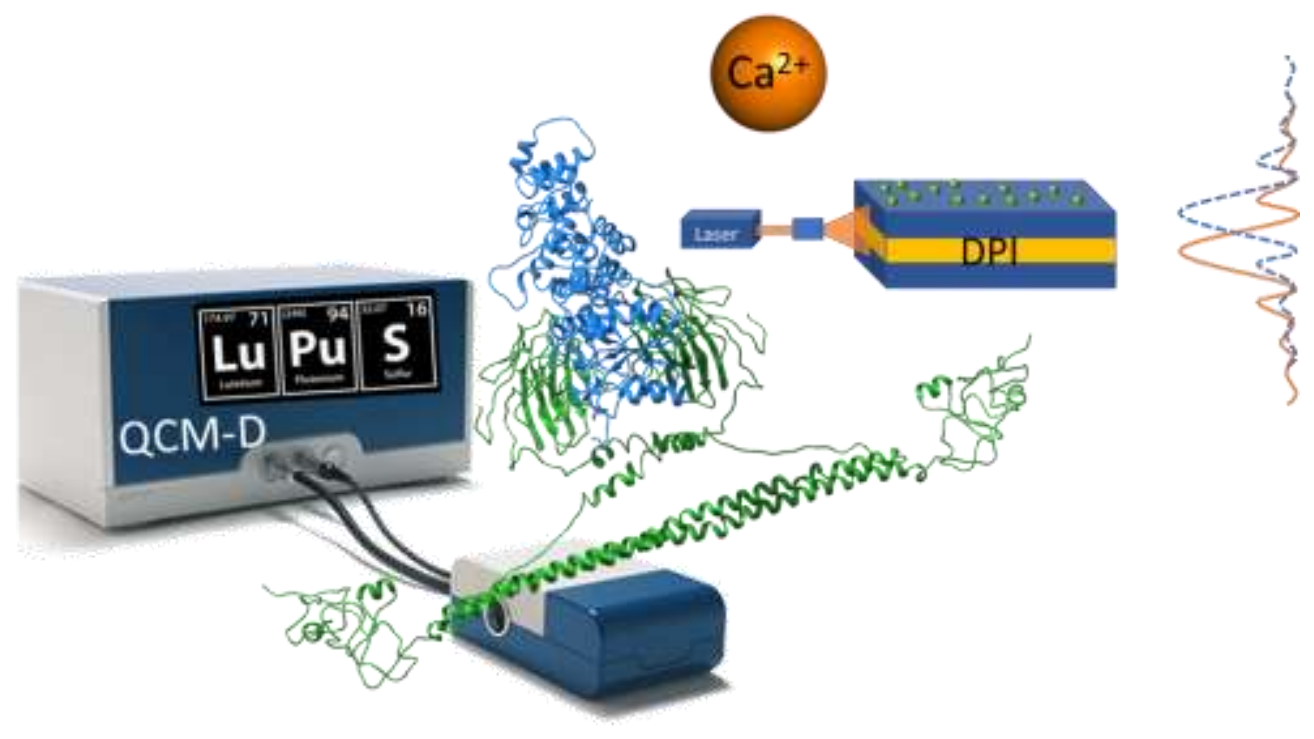




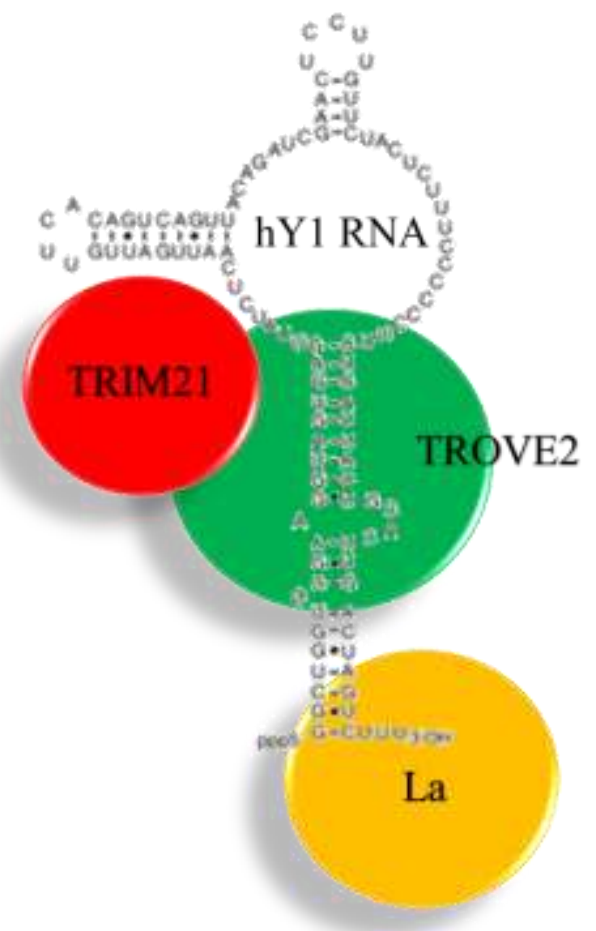

Figure 1.- Scheme of the Ro/SSA RNP complex. 
a)

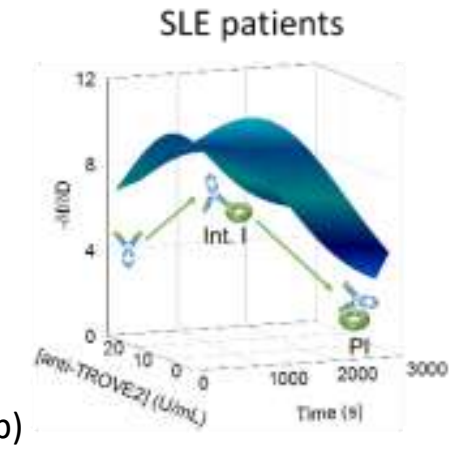

b)

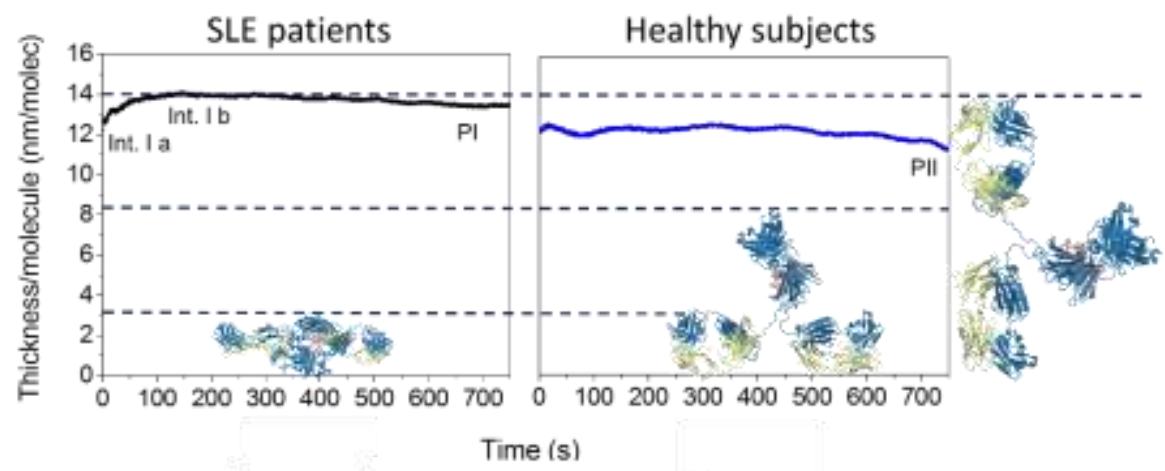

Figure 2.- Response of the TROVE2-based biosensors with respect to: a) - $\partial \mathrm{f} / \partial \mathrm{D}$ ratio for $\mathrm{IgG}$ from sera of SLE patients ([SLE hIgG] $=18.91 \mathrm{U} / \mathrm{mL}$, left) and healthy subjects $([$ control $\mathrm{hIgG}]=12.39 \mathrm{U} / \mathrm{mL}$, right $) . \mathrm{b})$ DPI values of thickness per molecule monitored during the hIgGs:TROVE2 biorecognition for SLE patients (left and black, [SLE hIgG] $=4.43 \mathrm{U} / \mathrm{mL}$ ) and healthy subjects (right and blue, [control hIgG] $=15.48 \mathrm{U} / \mathrm{mL}$ ). The antibody structures show the theoretical thicknesses per molecule of different orientations of the antibody molecules on the DPI sensor surface. 
a)
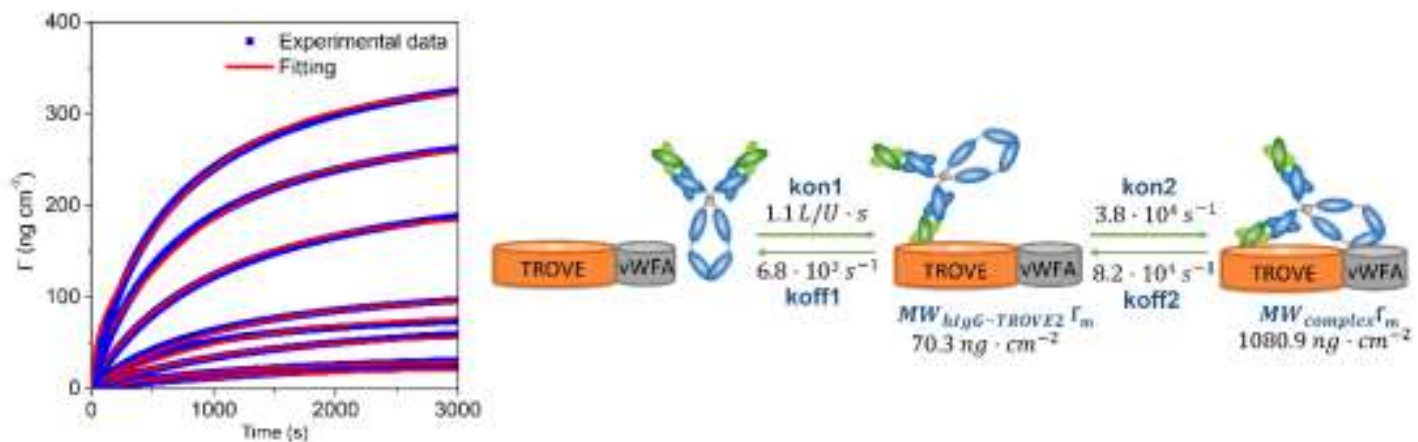

b)
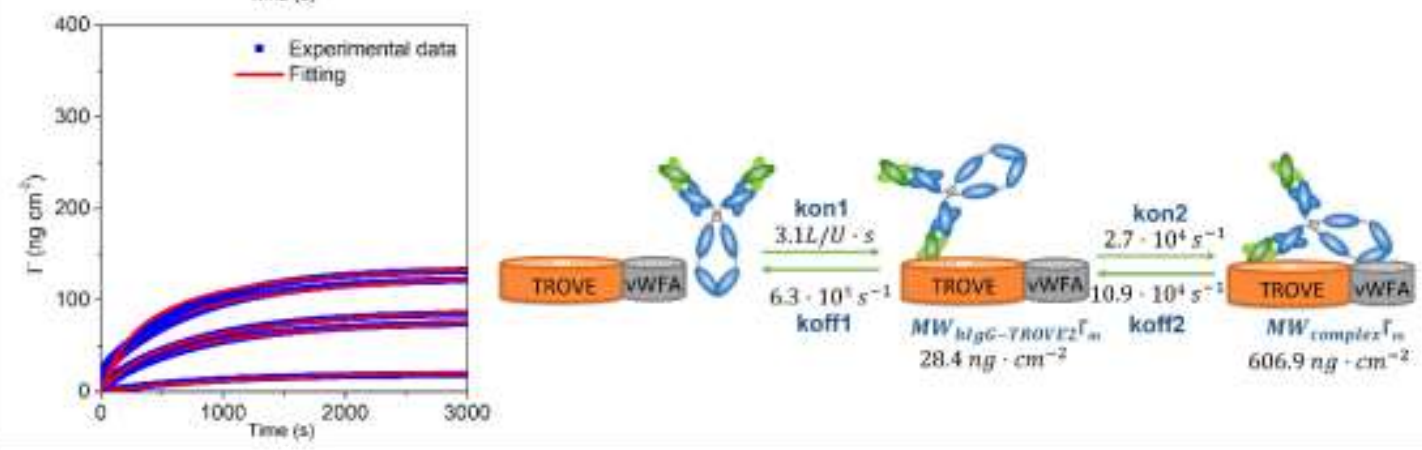

Figure 3.- Real time relaxation curves ( $\Delta \Gamma$ evolution as function of time) of the hIgG-TROVE2 interaction for different antibody concentrations obtained from sera of a) SLE patients and b) healthy subjects. Red lines are the fittings from the kinetic parameters shown on the reaction mechanism. Only one point from ten measured points was taken for all plots. 
a)

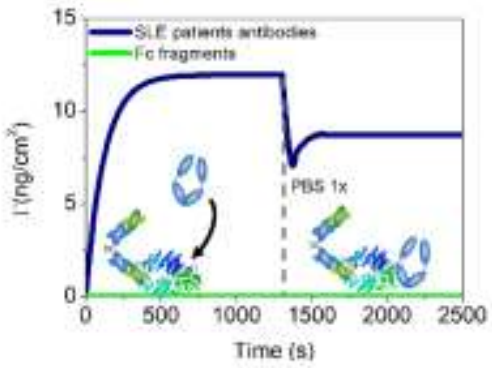

b)

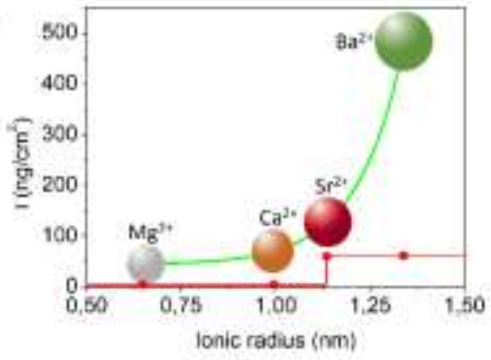

c)

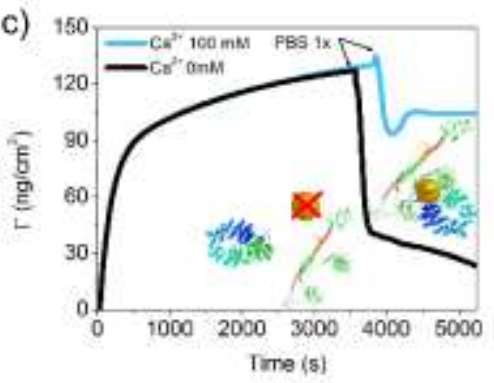

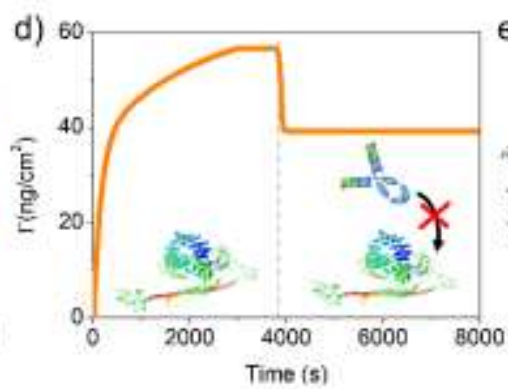

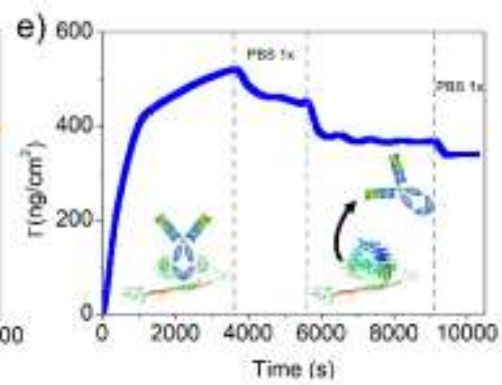

Figure 4.- a) Detection of $\mathrm{Fc}$ fragments by the TROVE2 protein previous (blue), or not (green), interaction with $\left.\mathrm{F}(\mathrm{ab})_{2}\right)_{2}$ fragments. $\left.\mathrm{b}\right)$ Influence of the ionic radii of alkaline earth ions in the detection of $\mathrm{Fc}$ fragments. Red line represents the nonspecific interactions with BSA. c) TRIM21-TROVE2 interaction in presence ([TRIM21 $\alpha]=50 \mathrm{mg} / \mathrm{L}$, blue) and absence ([TRIM21 $\alpha]=300 \mathrm{mg} / \mathrm{L}$, black) of calcium ions. d) Antibody biorecognition ( $12.5 \mathrm{U} / \mathrm{mL})$ by TRIM21 previously blocked with TROVE2. e) TROVE2 biorecognition $(50 \mu \mathrm{g} / \mathrm{mL})$ by TRIM21 previously blocked with control antibodies (12.5 $\mathrm{U} / \mathrm{mL})$. 
a)

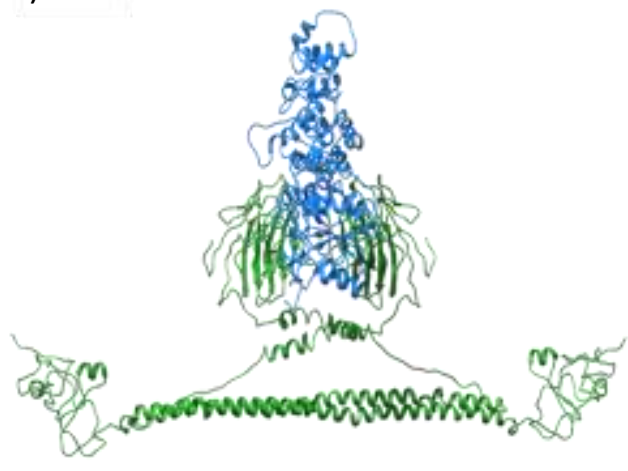

b)

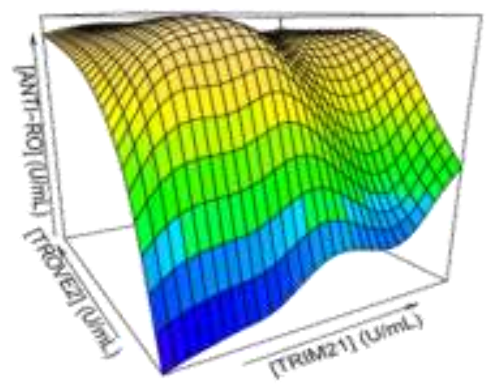

c)
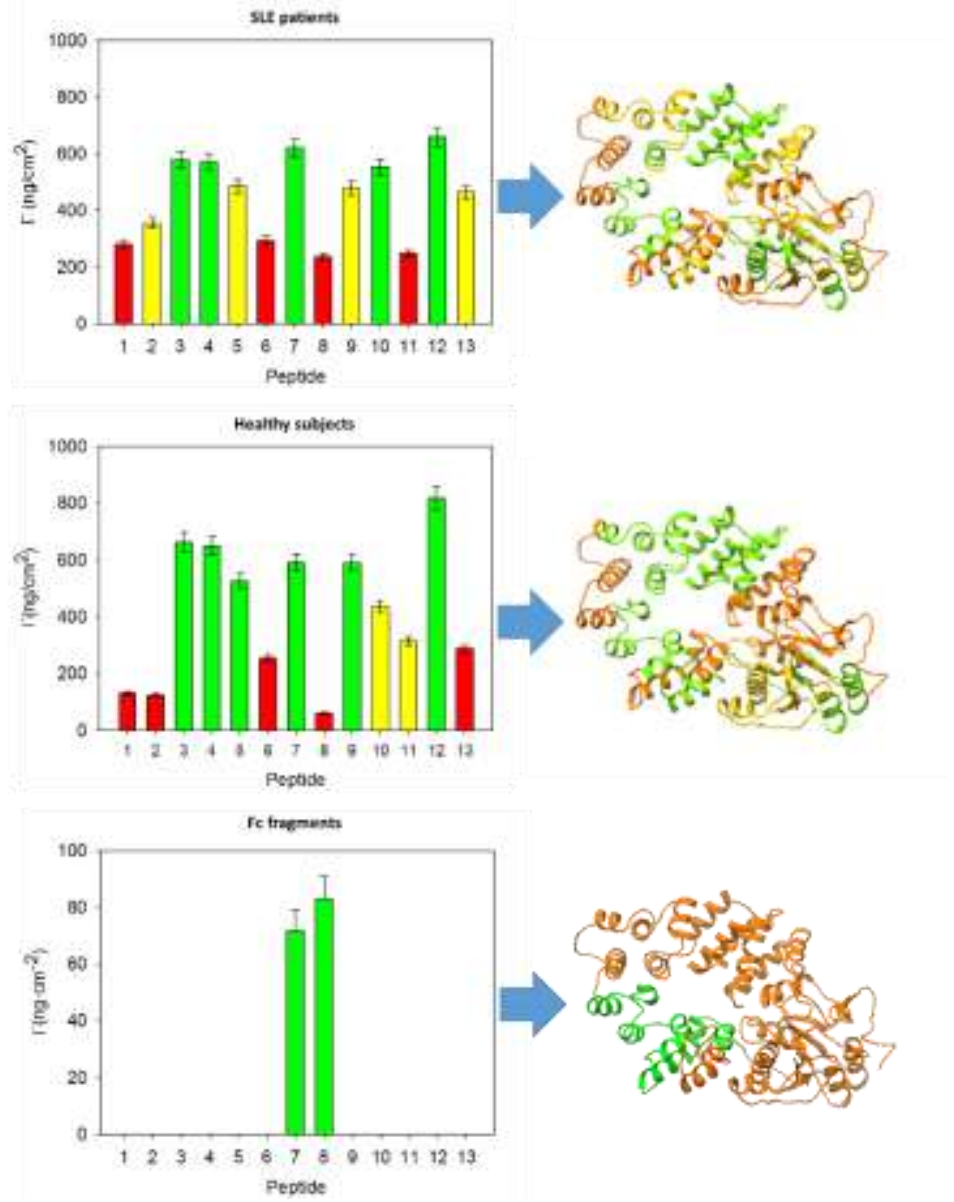

Figure 5.- a) The TRIM21-TROVE2 binding scheme. b) Correlation for serum levels of anti-TROVE2 and antiTRIM21 with levels of anti-Ro (full complex). c) Interaction of different TROVE2 polypeptides (see numeric code in Supplementary Table 4) with hIgGs obtained from SLE patients and healthy subjects as well as with Fc fragments. The binding sites are localized in the TROVE2 tertiary structure with the same color code than the corresponding bar chart. 